\title{
The Role of Functional Synchronization of Alpha Waves in Divergent and Convergent Thinking
}

\section{Emad Aazr, Imanollah Bigdeli*, Ali Ghanaei Chamanabad}

Department of Psychology, Faculty of Psychology and Educational Sciences, Ferdowsi University of Mashhad, Mashhad, Iran

\section{A BSTRACT}

Introduction: Alpha frequency band in the range of 8-12 $\mathrm{Hz}$ is associated with cognitive functions, such as creativity. The aim of this study was to examine the activity of the alpha frequency band in two divergent and convergent thinking positions. Materials and Methods: In accordance to the available sampling and voluntary participation, thirty-eight postgraduate students of the Ferdowsi University of Mashhad (19 males and 19 female) were chosen. Two subjects were excluded from the analysis due to artifacts in their brain waves. This study was a quasi-experimental research with repeated measures. The EEG was recorded during the performance of four tasks (alternative uses test, counting the snakes, counting numbers test, and Missionaries and Cannibals task) in two divergent and convergent thinking. Results: The findings revealed that there is no significant difference between the activity of alpha waves in the left and right hemispheres in divergent thinking as well as in convergent thinking. In addition, the results of the analysis of variance of repeated measures indicated that in divergent thinking activity of alpha waves in the temporal, central and frontal areas were synchronized, while in the convergent thinking position de-synchronization of alpha waves was observed. Conclusion: Alpha band power changes in two divergent and convergent thinking positions represented of different functional mechanisms of alpha waves in these two thinking positions in different regions of the brain.

Key words:

1. Electroencephalography

2. Brain

3. Thinking

*Corresponding Author: Imanollah Bigdeli

E-mail:ibigdeli@um.ac.ir 


\title{
نقش كاركردى همعامسازى فعاليت امواج آلفا در تفكر واكرا و همكرا
}

\author{
عماد آذر، ايمان الله بيعَلى"، على غنائى جمن آباد
}

كروه روانشناسى، دانشكده علوم تربيتى و روانشناسى، دانشگاه فردوسى مشهد، مشهد، ايران

\section{اطلاعات مقاله:}

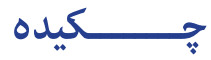

مقدمه: باند فر كانسى آلفا در محدوده كا | -1 هرتز با كاركردهاى شناختى مانند خلاقيت در ارتباط مى باشد.

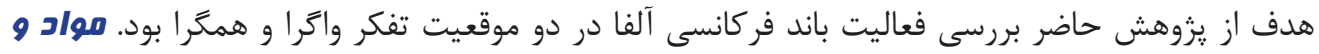
روشأها: بر اساس نمونه

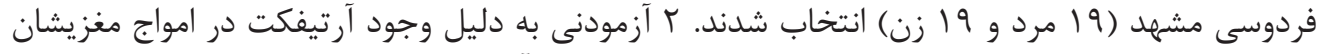

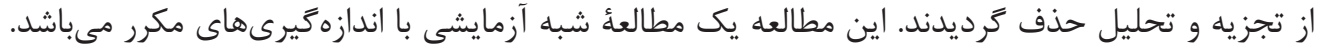

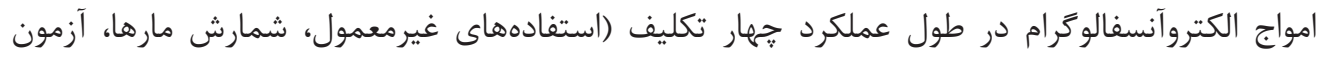

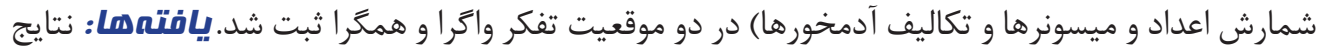

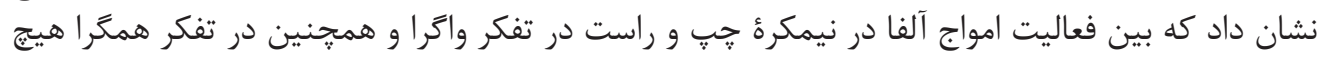

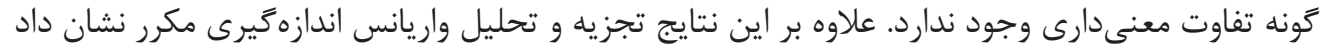

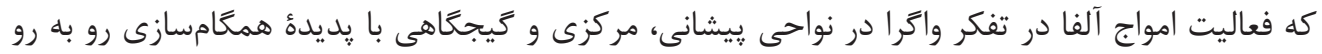

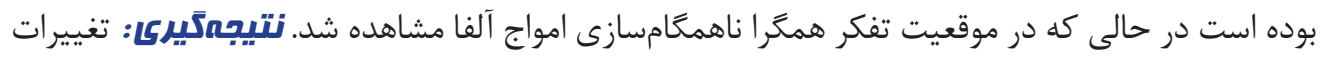

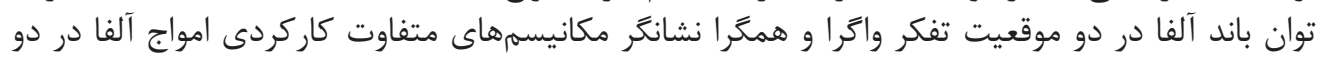
موقعيت تفكر در نواحى مختلف مغز مى بـاشد. 


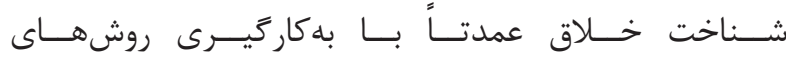

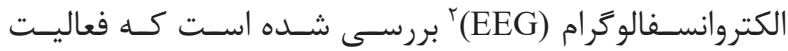

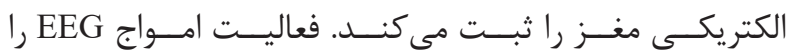

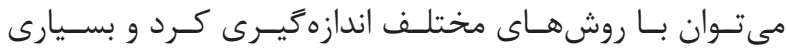

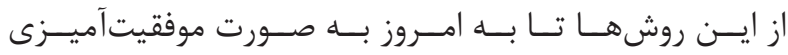

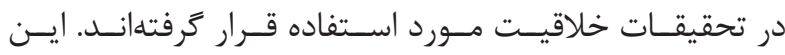

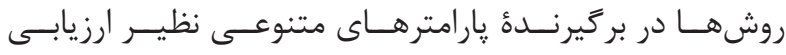

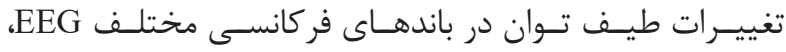

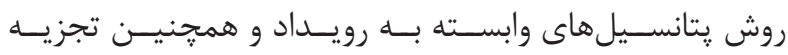

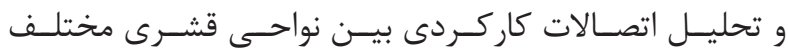

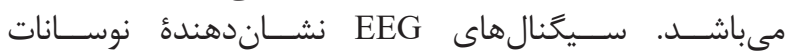

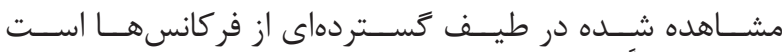

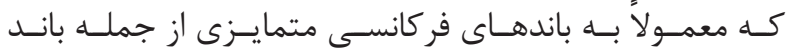

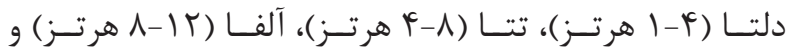

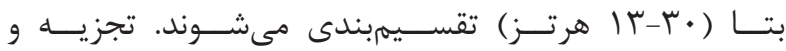

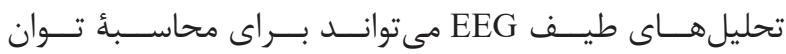

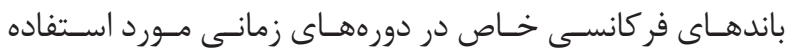

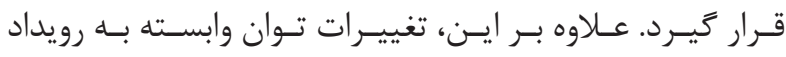

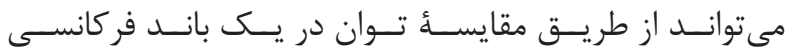

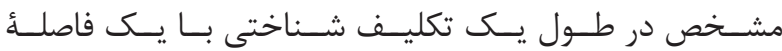

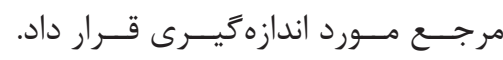

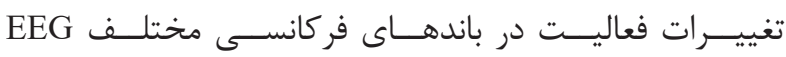

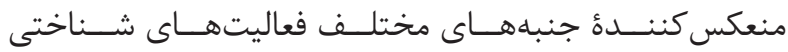

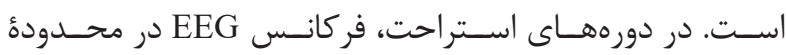

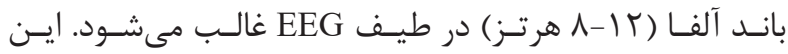

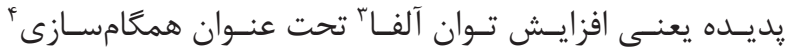

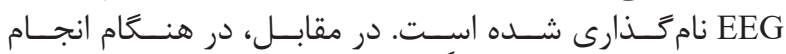

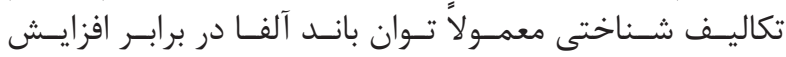

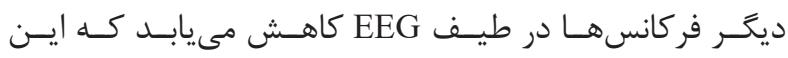

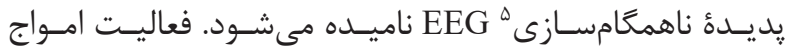

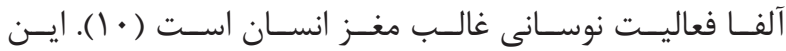

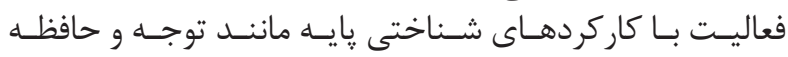

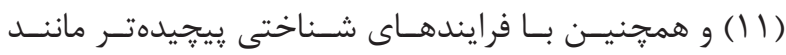

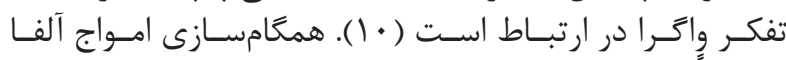

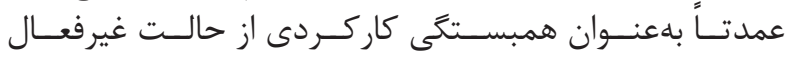

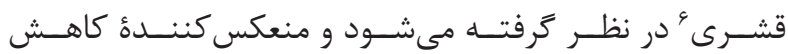

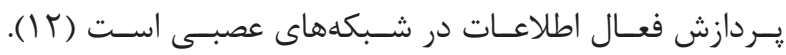

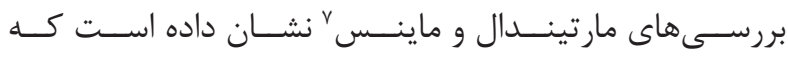

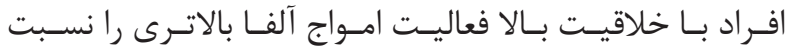

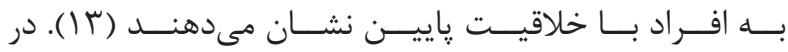

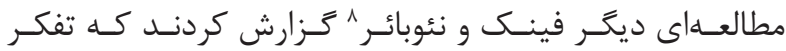

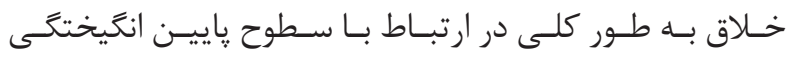

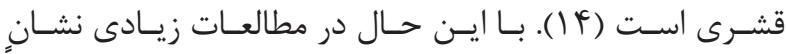

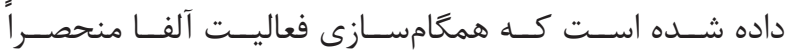

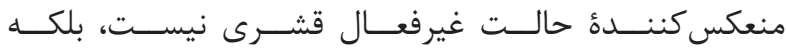

${ }^{1}$ Unusual uses test

${ }^{2}$ Electroencephalogram

${ }^{3}$ Alpha power

${ }^{4}$ Synchronization
مقدمه

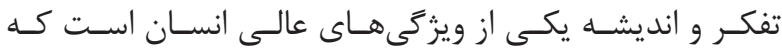

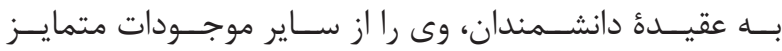

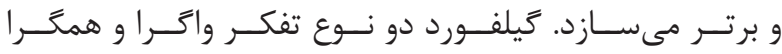

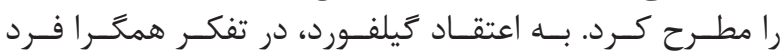

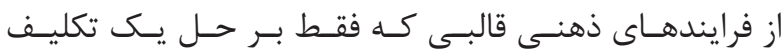

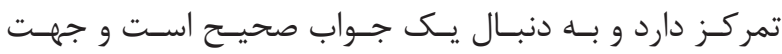

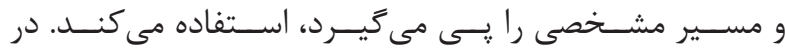

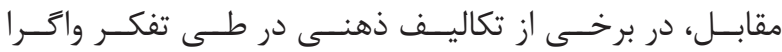

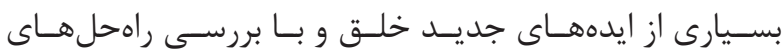

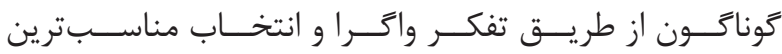

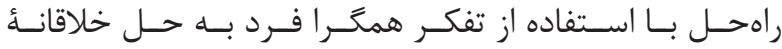

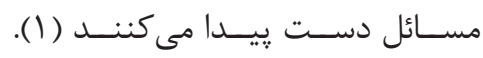

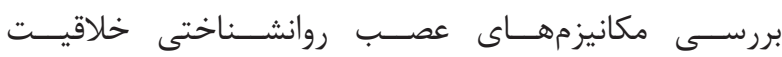

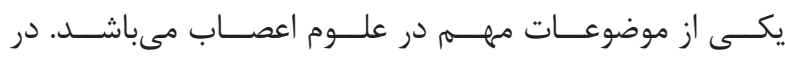

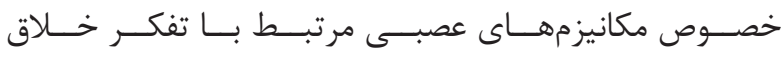

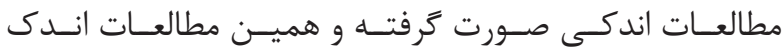

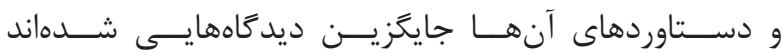

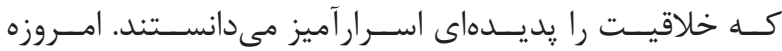

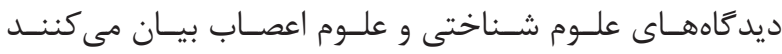

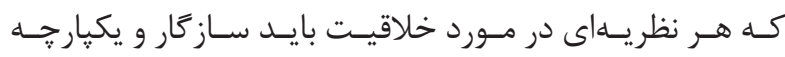

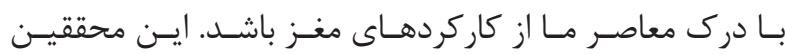

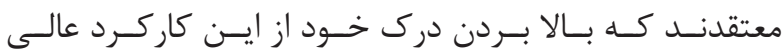

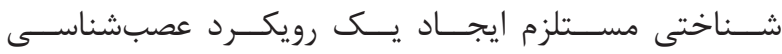

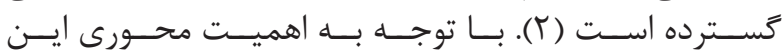

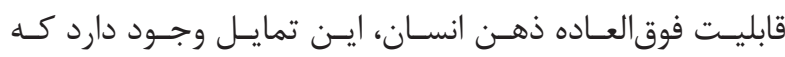

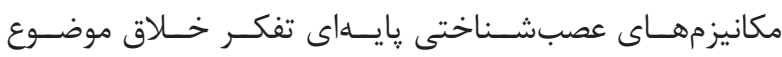

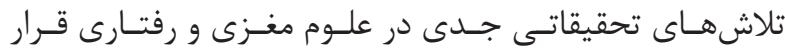

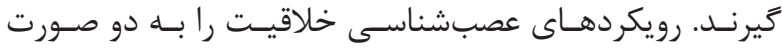

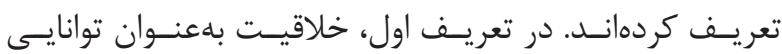

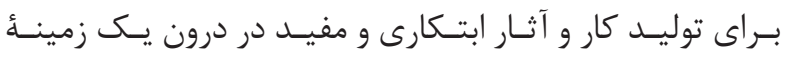

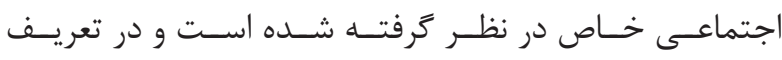

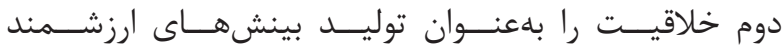

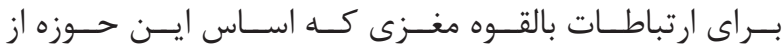

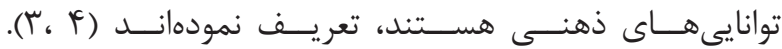

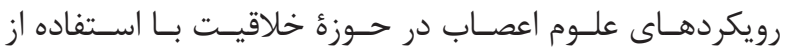

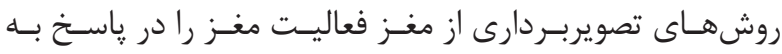

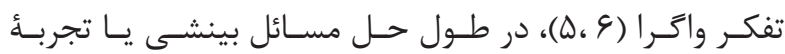

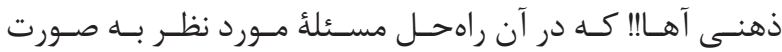

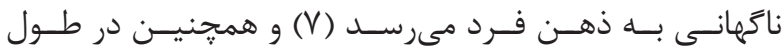

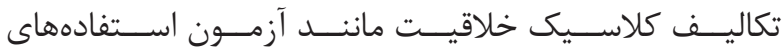

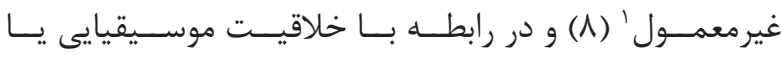

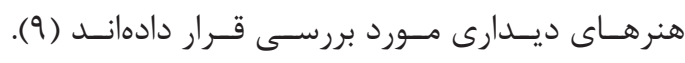
جنبههـــاى مختلــف اساســى و يايــــاى ارتباطــات مغنـزى

${ }^{5}$ De- synchronization

${ }^{6}$ Cortical idling

${ }^{7}$ Martindale and Mines

${ }^{8}$ Neubauer 


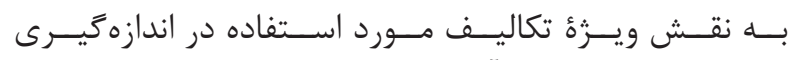

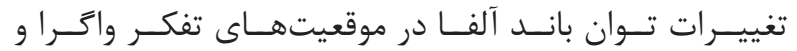

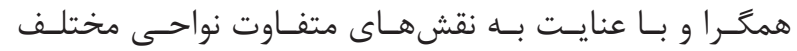

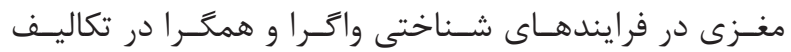

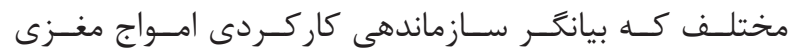

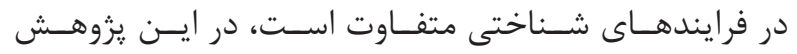

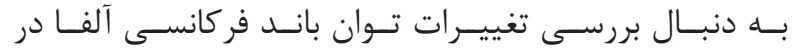

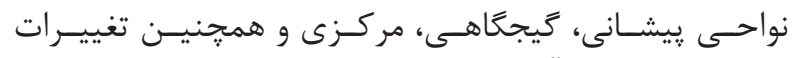

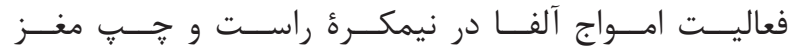

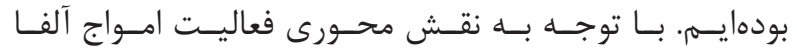

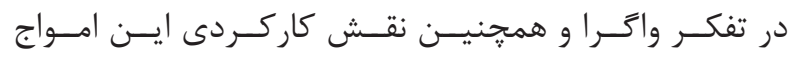

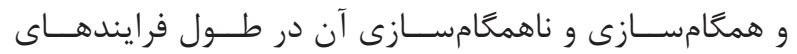

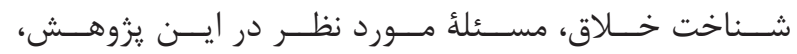

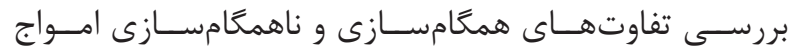

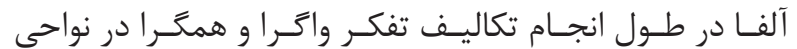

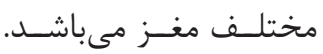

\section{مواد و روشها - - ماد}

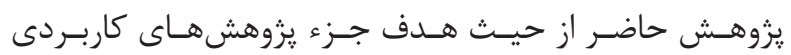

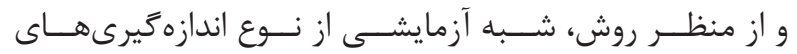

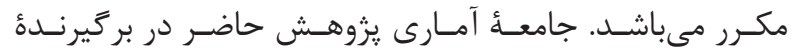

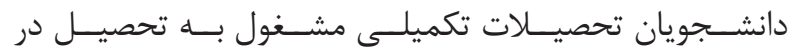

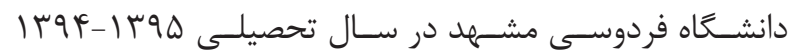

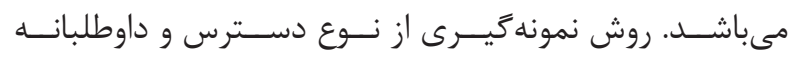

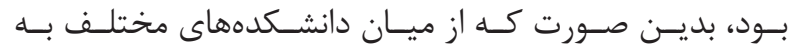

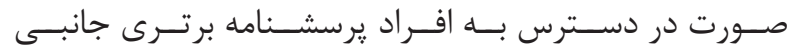

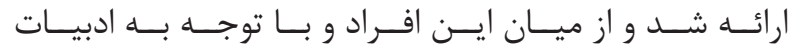

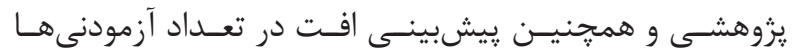

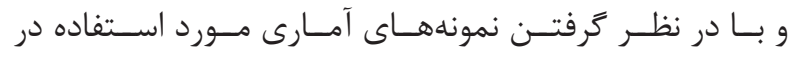

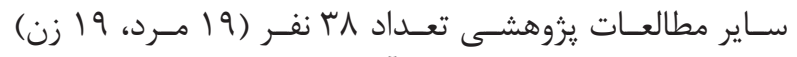

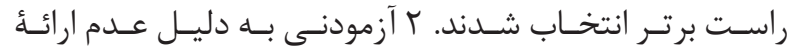

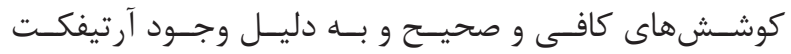

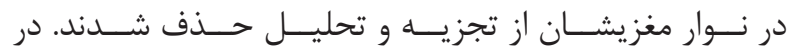

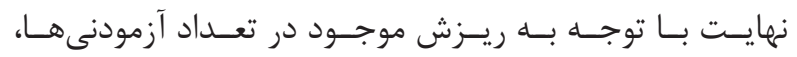

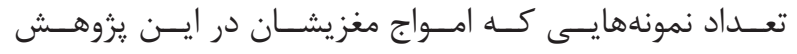

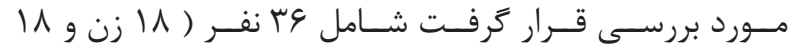

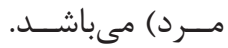

$$
\begin{aligned}
& \text { ابزارهاى يُزوهش }
\end{aligned}
$$

\section{يرسشنامةٔ برترى جانبى}

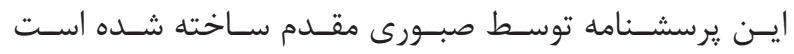

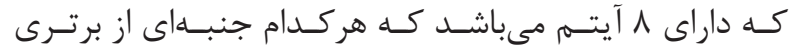

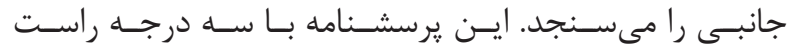

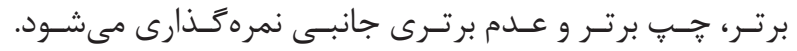

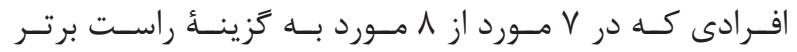

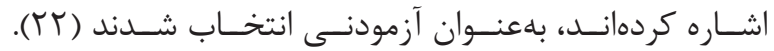

\footnotetext{
${ }^{9}$ Mental imanigation

${ }^{10}$ Internally-directed attention

${ }^{11}$ Power

${ }^{12}$ Sensory-intake tasks
}

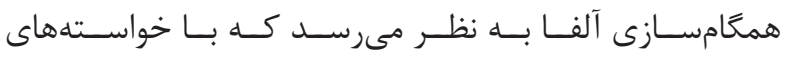

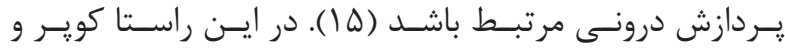

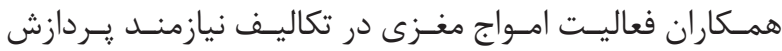

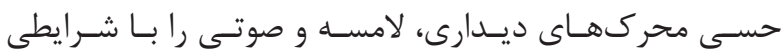

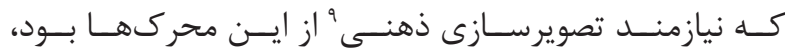

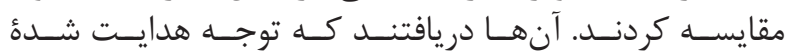

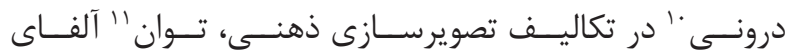

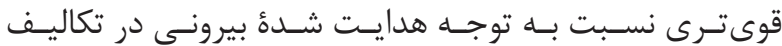

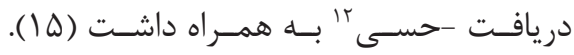

تــا بـــهـ امـــروز مطالعــات مختلفــى از روش همعامســازى

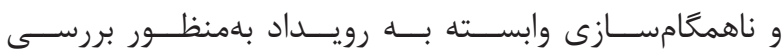

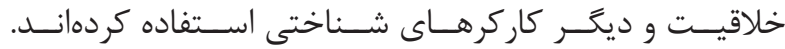

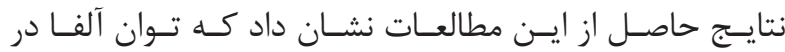

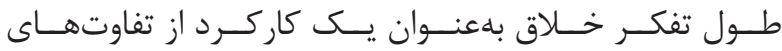

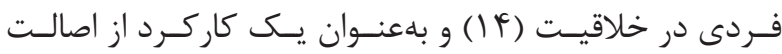

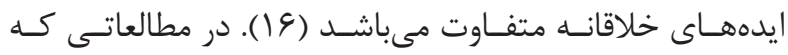

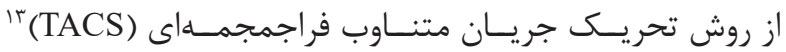

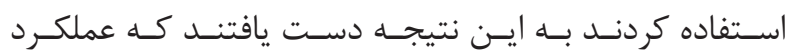

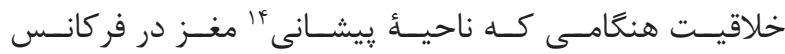

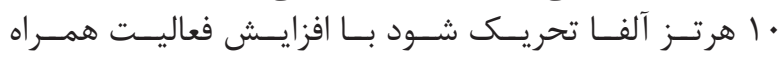

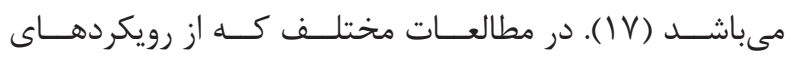

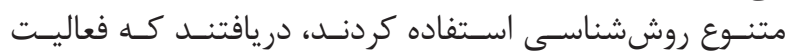

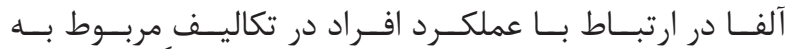

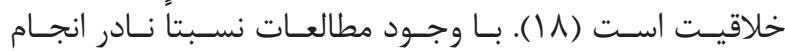

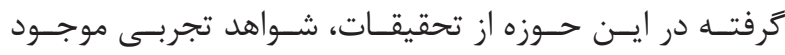

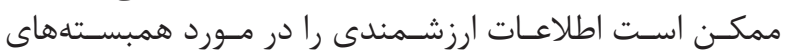

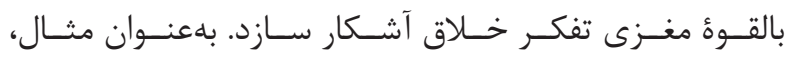

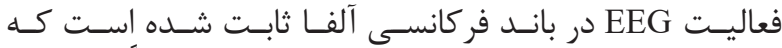

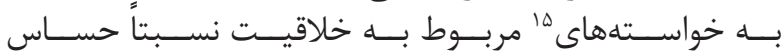

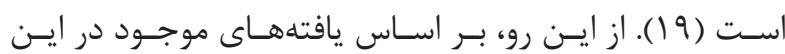

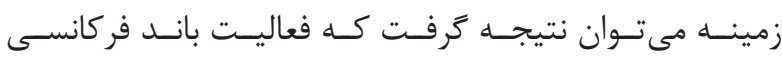

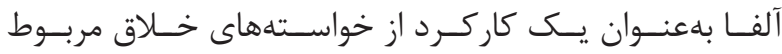

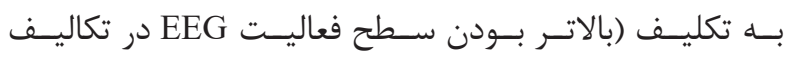

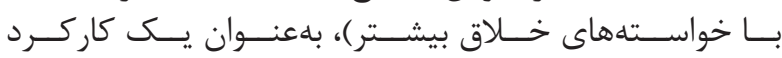

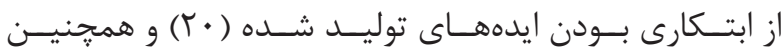

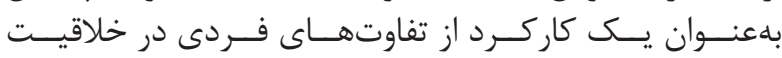

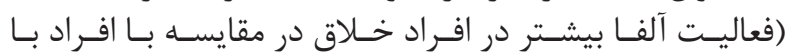

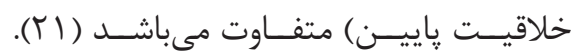

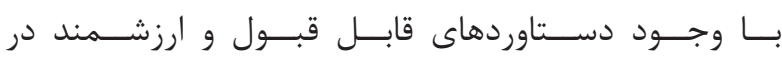

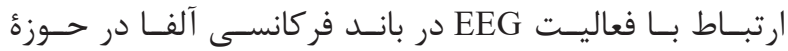

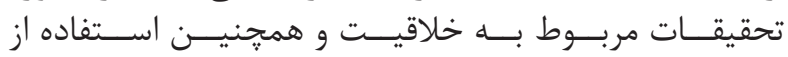

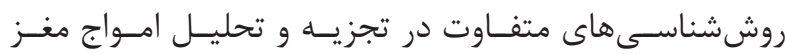

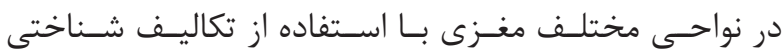

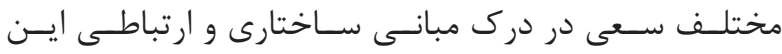

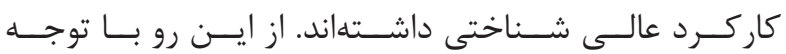

${ }^{13}$ Transcranial alternating current stimulation

${ }^{14}$ Frontal

${ }^{15}$ Demands 


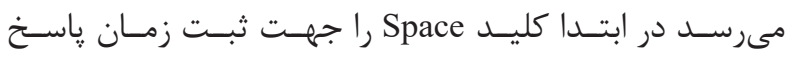

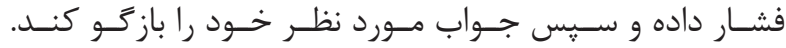

$$
\text { روش اجراى نبزوهش }
$$

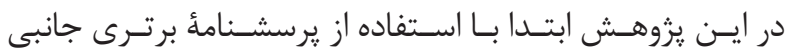

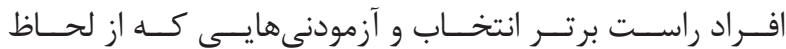

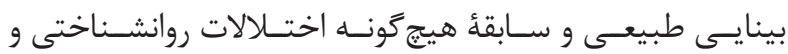

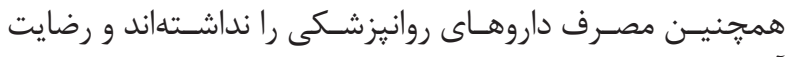

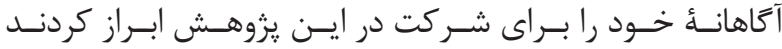

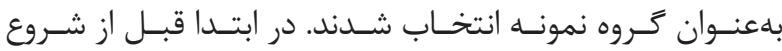

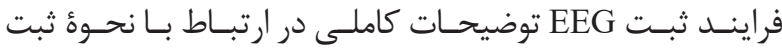

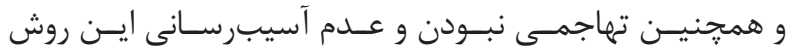

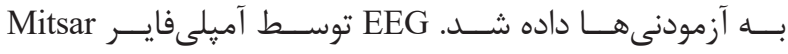

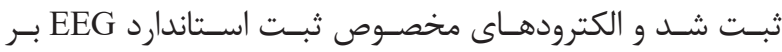

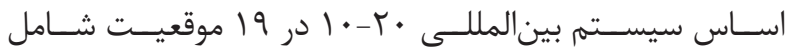
F3، Fz، F4، F8، T3، C3، Cz، C4، T4، ‘Fp1، Fp2، F7) (T5، P3، Pz، P4، T6، O1، O2

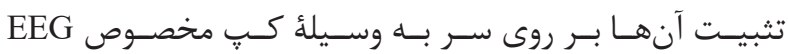

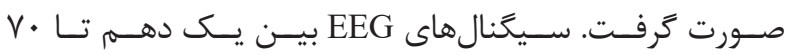

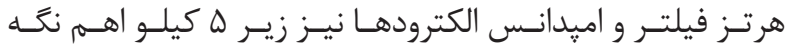

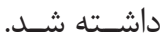

تكاليـف اسـتفاده شـده در ايـن يروهـــ در دو موقعيـت تفكـر

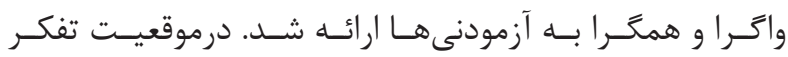

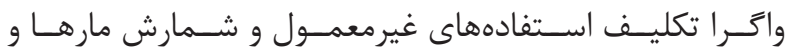

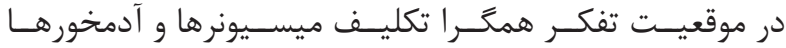

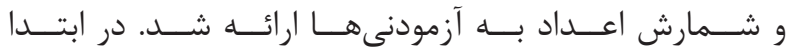

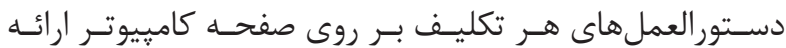

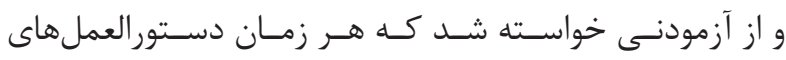

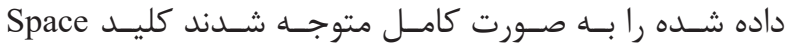

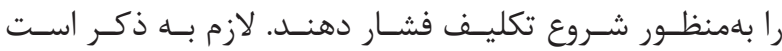

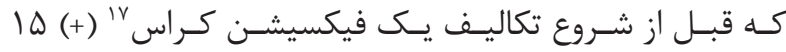

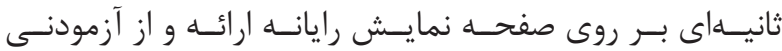

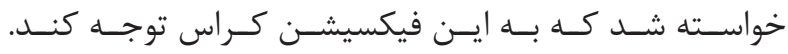

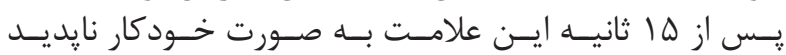

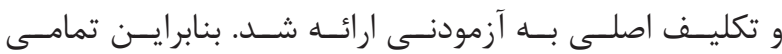

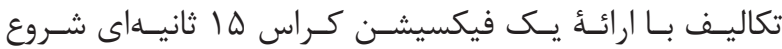

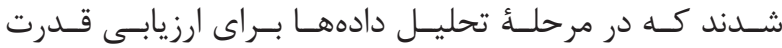

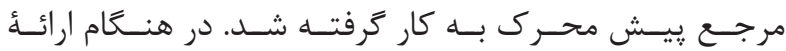

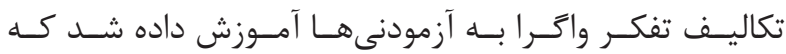

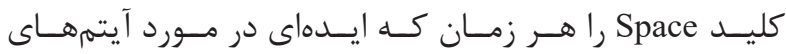

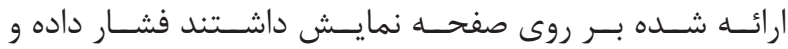

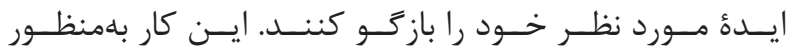

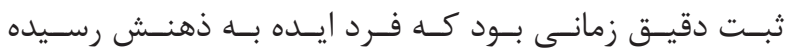

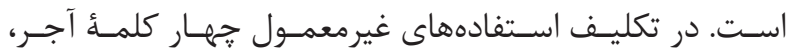

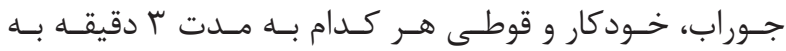

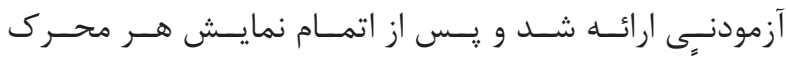

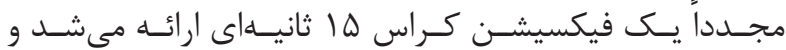

\section{الكتروانسفالو گر افى كمى}

در الكتروانســفالوكرافى كمــى (QEEG) امـواج مغـزى از آميلىفايــ Mitsar و از كلاه

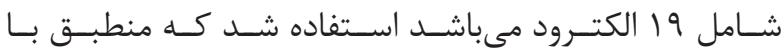

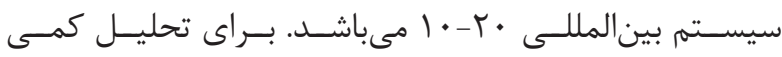

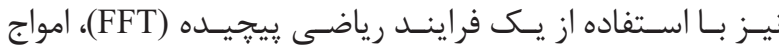

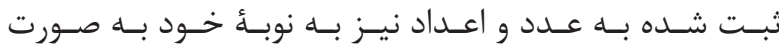

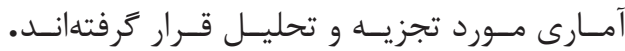

\section{تكليف ميسيونر ها و آدمخورها}

ايـن تكليـف شـامل انتقــال ســه ميســيونر و ســهـ آدمخــور

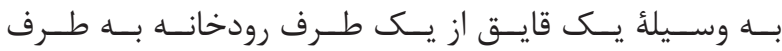

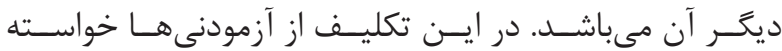

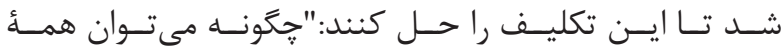

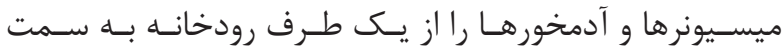

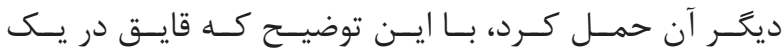

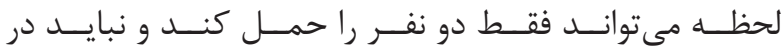

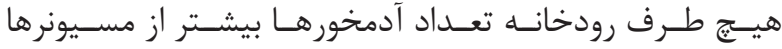

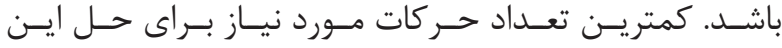

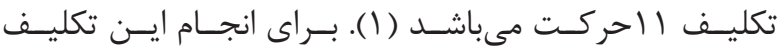

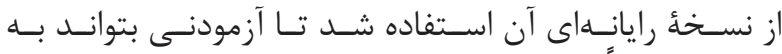

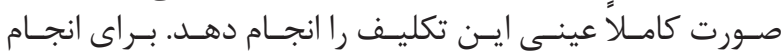

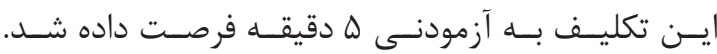

\section{تكليف شمارش اعداد}

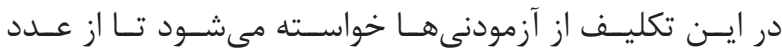

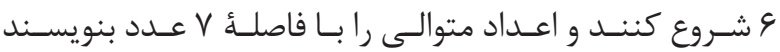

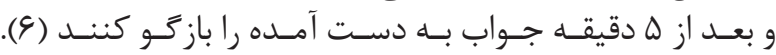

تكليف شمارش مارها

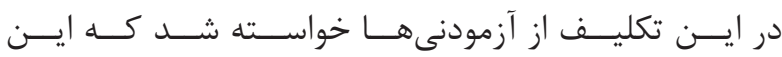

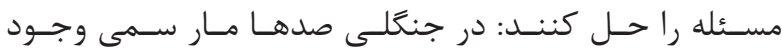

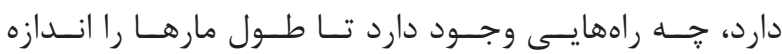

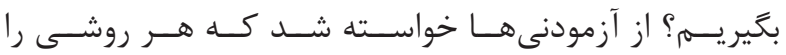

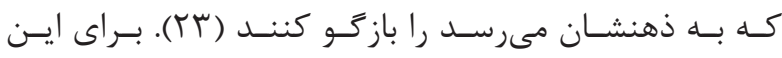

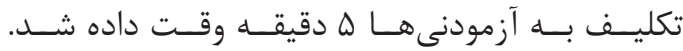

\section{تكليف استفادههاى غيرمعمول}

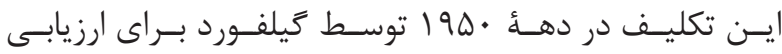

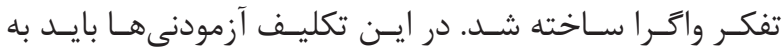

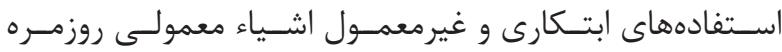

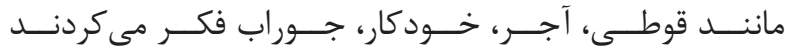

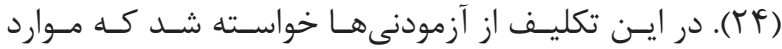

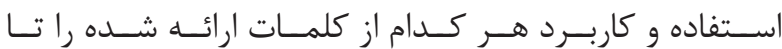

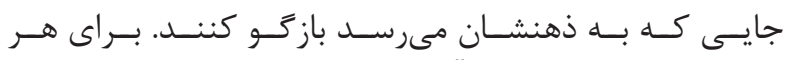

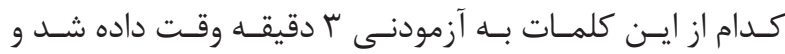

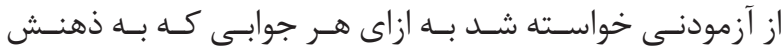




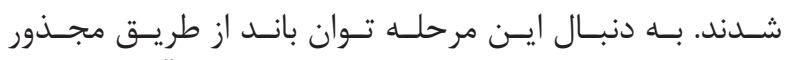

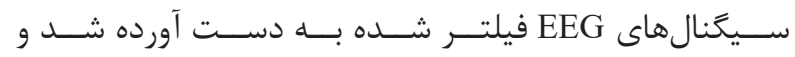

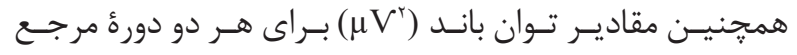

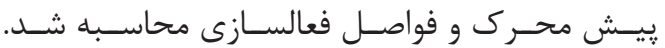
تجزيه و تحليل دادهها

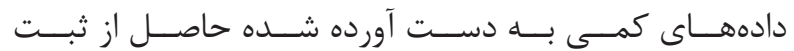

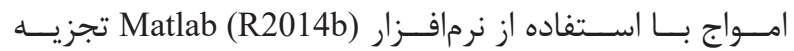

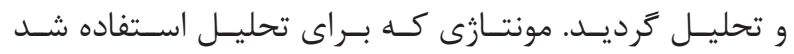

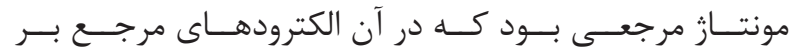

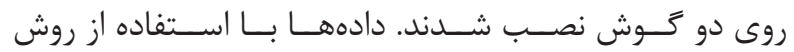

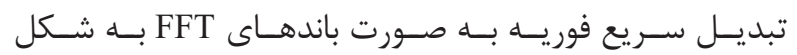

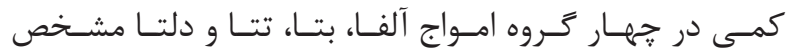

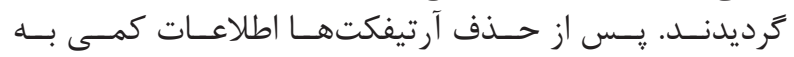

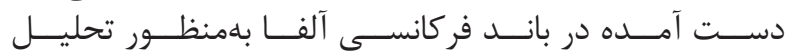

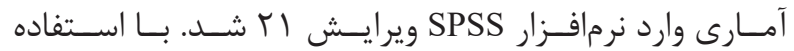

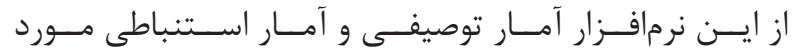

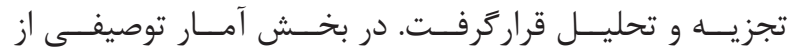

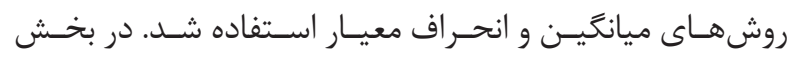

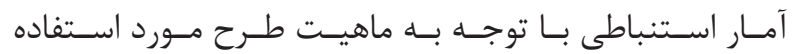

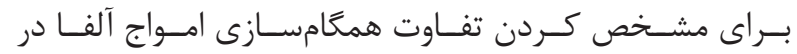

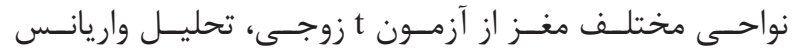

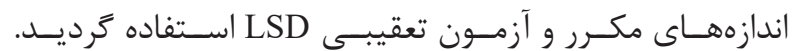

بافتهها

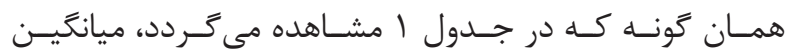

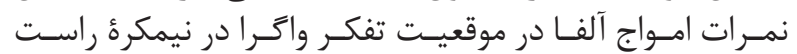

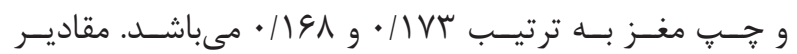

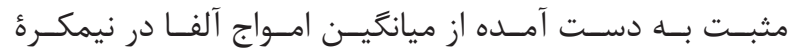

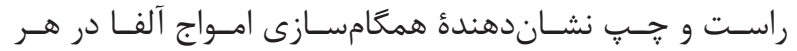

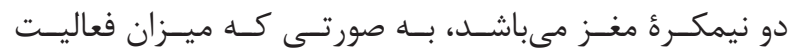

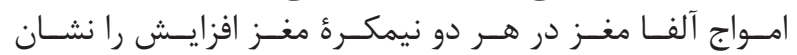

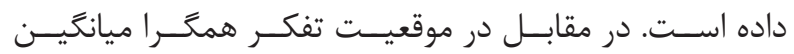

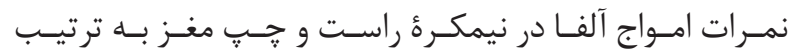

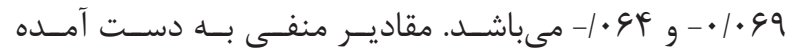

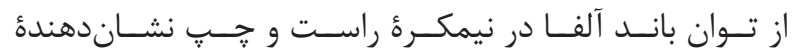

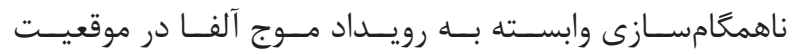

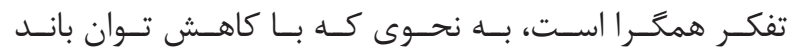

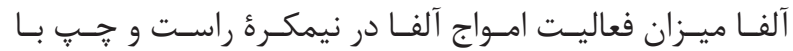

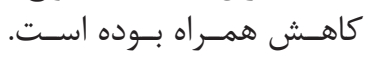

بهمنظــور بررسـى معنــى دار بـودن تغييـرات تــوان بانـد آلفــا

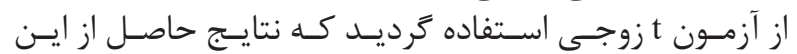

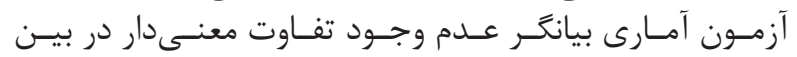

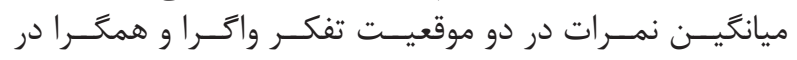

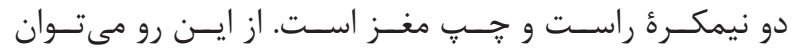

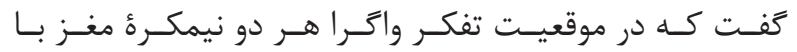

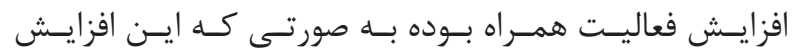

\footnotetext{
${ }^{18}$ Task-related power

${ }^{19}$ Power activation
}

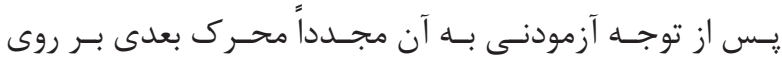

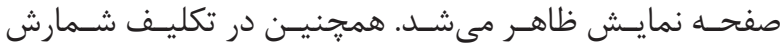

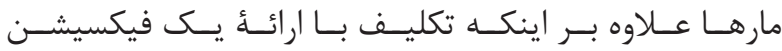

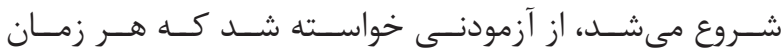

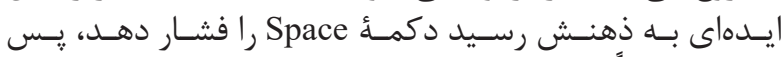

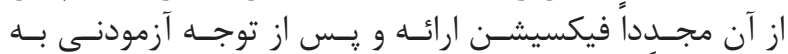

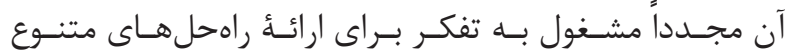

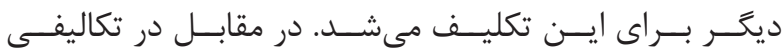

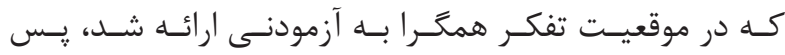

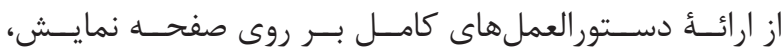

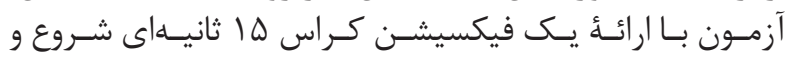

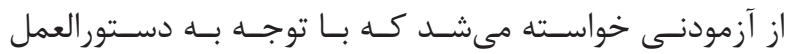

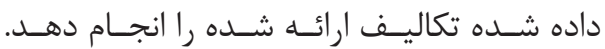

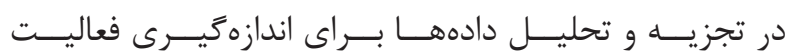

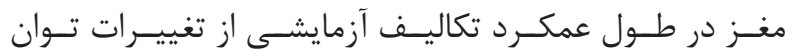

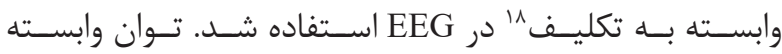

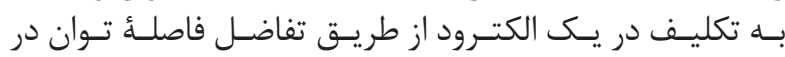

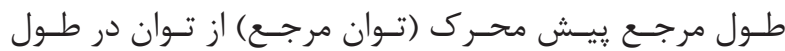

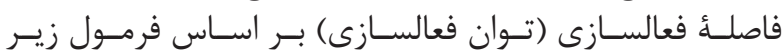

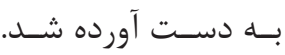

$\operatorname{TRP}\left(\log \mathrm{Pow}_{i}\right)=\log \left[\mathrm{Pow}_{i \text { (activation) })}\right]-\log \left[\mathrm{Pow}_{i \text { (reference })}\right]$

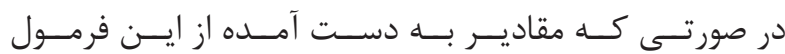

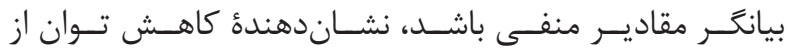

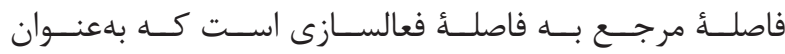

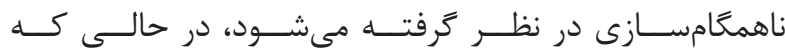

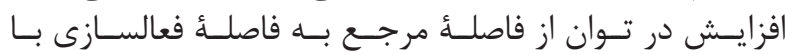

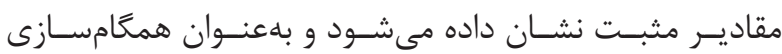

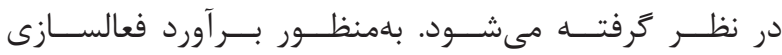

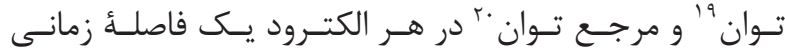

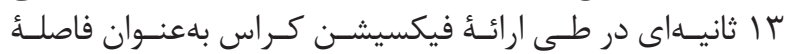

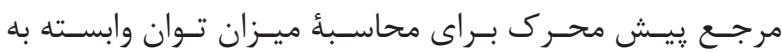

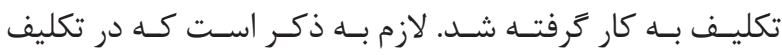

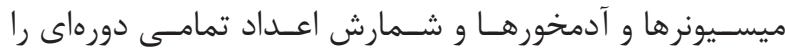

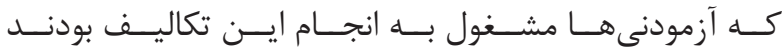

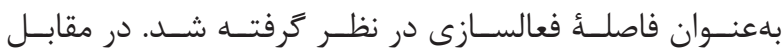

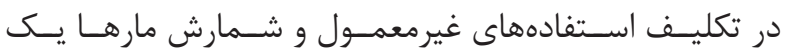

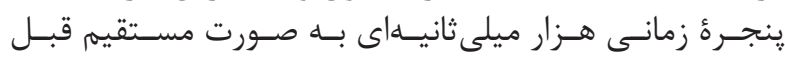

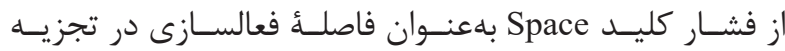

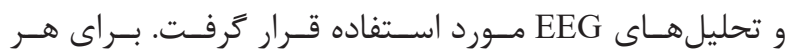

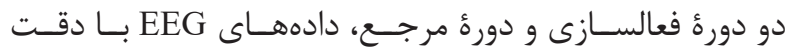

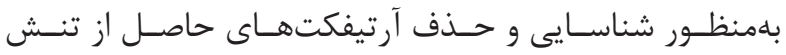

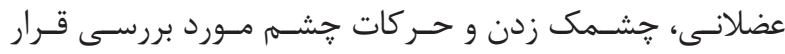

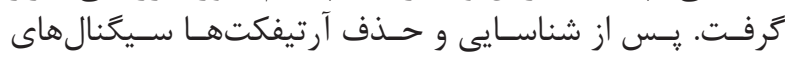

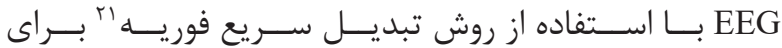

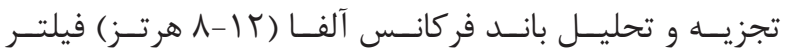

${ }^{20}$ Power reference

${ }^{21}$ Fast fourier transform 
جدول ا- شاخصهاى توصيفى مربوط به فعاليت امواج آلفا در نيمكرة راست و جِب در دو موقعيت تفكر همكرا و واكرا.

\begin{tabular}{|c|c|c|c|c|c|}
\hline انحراف معيار & ميانگين & ت عداد & \multicolumn{2}{|c|}{ متغير } & \multirow{5}{*}{ امواج آلفا } \\
\hline$\cdot / 11$. & ./IVT & re & نيمكرءٔ راست & \multirow{2}{*}{ تفكر واترا } & \\
\hline$\cdot / 1 \wedge \Delta$ & $+119 \Lambda$ & ק & نيمكره جي & & \\
\hline.$|19|$ & -.1 .99 & ع & نيمكرء راست & تفكر & \\
\hline$\cdot|| \Delta \mid$ & -.1 .94 & re & نيمكرهُ جِي & همخَرا & \\
\hline
\end{tabular}

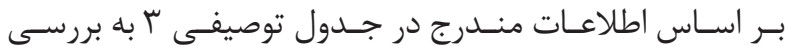

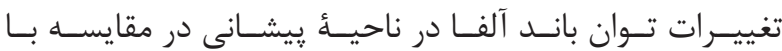

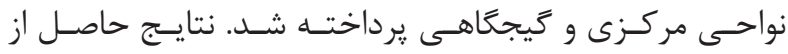

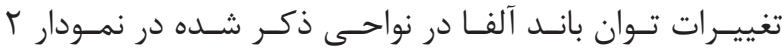

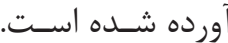

بلمنظظـور بررسـى معنــى دار بــودن تفــاوت تغييــرات تــوان

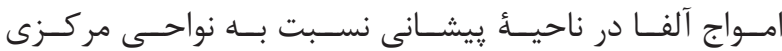

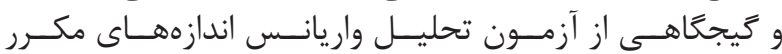

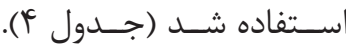

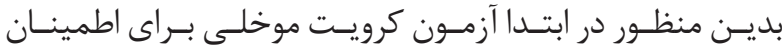

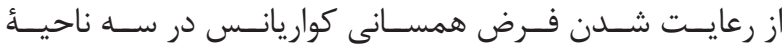

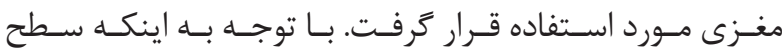

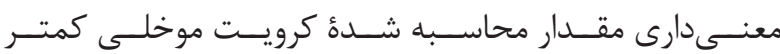

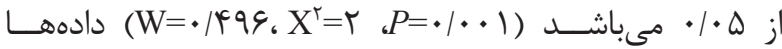

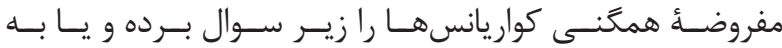

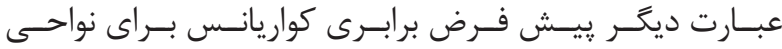

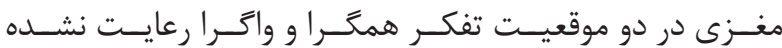

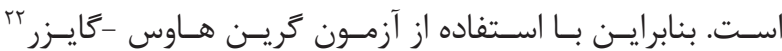

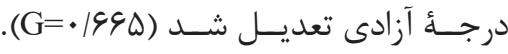

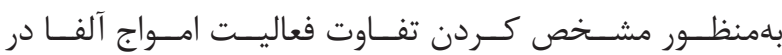

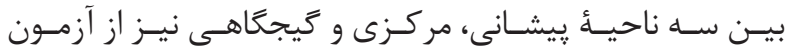

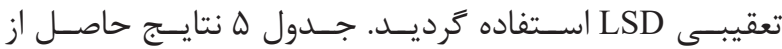

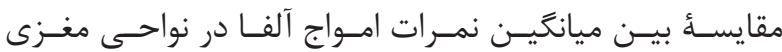

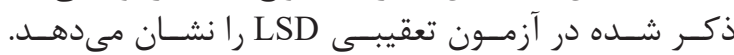

بــر اسـاس نتايــج منــدرج در جــدول ه، تفــاوت معنـى دارى

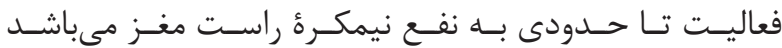

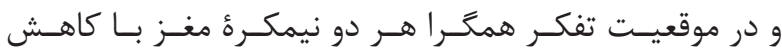

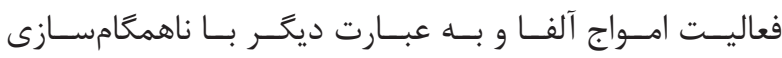

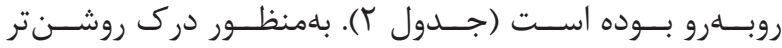

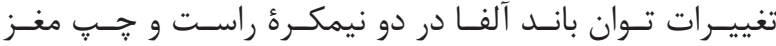

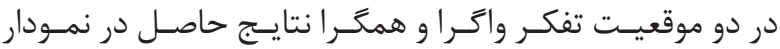

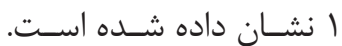

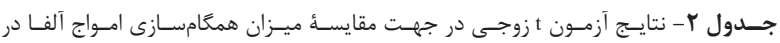

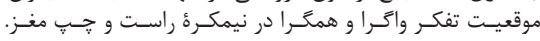

\begin{tabular}{|c|c|c|c|c|c|}
\hline $\mathbf{T}$ & سطح معنى دارى & درجة آزادى & \multicolumn{2}{|c|}{ متغير } & \multirow{3}{*}{ امواج آلفا } \\
\hline$\cdot / \Delta \cdot r$ &.$/ 919$ & ro & نيمكرةٔ ربب & تفكر واترا & \\
\hline & •/Vq. & Ta & نيمكرة جيب راست & تفكر همكرا & \\
\hline
\end{tabular}

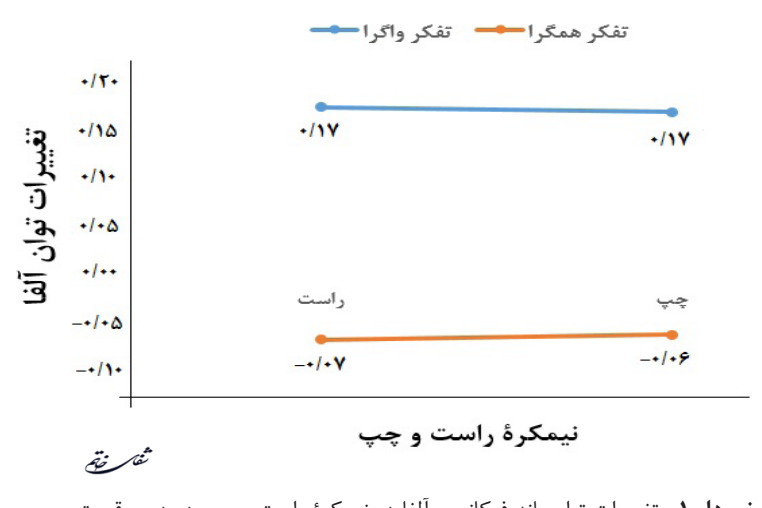

نمودار ا- تغييرات توان باند فركانسى آلفا در نيمكرءٔ راست و جٍٍ در دو موقعيت

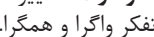

جدول بـ- شاخصهاى توصيفى مربوط به فعاليت امواج آلفا به تفكيك نواحى مغزى و نوع تفكر.

\begin{tabular}{|c|c|c|c|c|}
\hline انحراف معيار & ميانگين & تعداد & متغير & \\
\hline $.1 \cdot 91$ & $-\cdot 1 \cdot 1 \mathrm{ma}$ & קe & ناحية يِيشانى در تفكر همگرا & \multirow{6}{*}{ امواج آلفا } \\
\hline.$/ 1 \mathrm{ft}$ & $\cdot 1 \cdot \sqrt{ } \cdot 1$ & ge & ناحيئ بِيشانى در تفكر واكرا & \\
\hline.$/ 1 \mathrm{VT}$ & $-\cdot 1 \cdot \Delta f$ & G & ناحيـة مركزى در تفكر همكرا & \\
\hline .111 & $.|| v \mid$ & re & ناحيذ مركزى در تفكر واترا & \\
\hline - & $-\cdot 1 \cdot 94$ & re & ناحية كيجگَاهى در تفكر همغرا & \\
\hline$:|1 \wedge|$ & $\cdot / 1 \vee \cdot$ & re & ناحية كَيجمَاهى در تفكَر واكرا & \\
\hline
\end{tabular}

${ }^{22}$ Greenhouse-geisser 


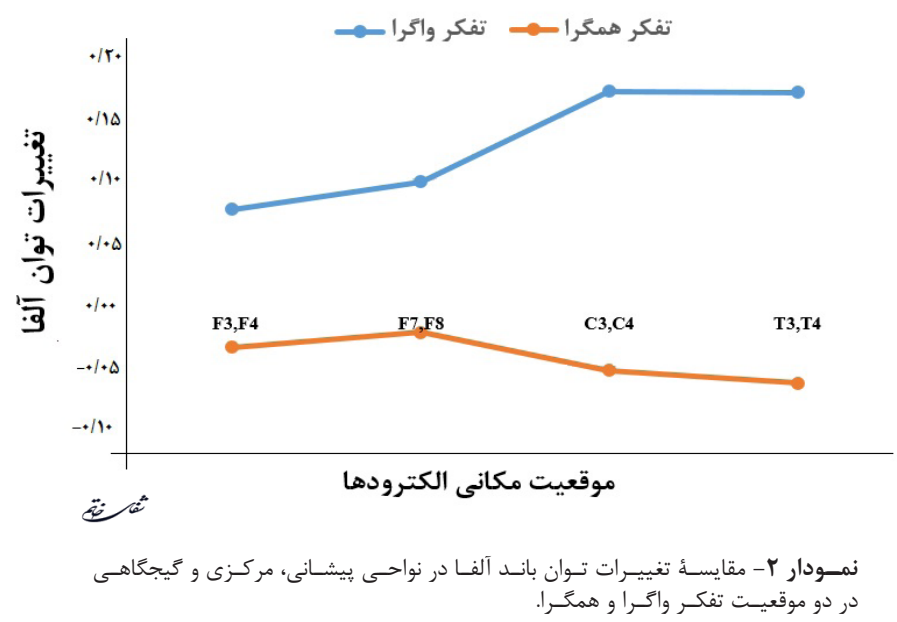

جدول F- خلاصؤ تحليل واريانس بهمنظور بررسى فعاليت امواج آلفا در نواحى مختلف مغزى و نوع تفكر.

\begin{tabular}{|c|c|c|c|c|c|c|c|}
\hline اندازة اثر & سطح معنى دارى & $\mathbf{F}$ & ميانكين مربعات & درجة آزادى & مجموع مربعات & منابع تغيير & متغير \\
\hline$\cdot / 14$ & $\cdot 1 \cdot r q$ & $h / . t t$ & $\begin{array}{l}\cdot / \cdot r T \\
\cdot / \cdot \Lambda\end{array}$ & $\begin{array}{c}1 / V 11 \\
\text { ब9/AAD }\end{array}$ & $\begin{array}{l}\cdot / \cdot \Delta V \\
\cdot / f \Delta \varphi\end{array}$ & شرايط & ل لوب \\
\hline$\cdot / 491$ & $\cdot 1 \cdots 1$ & ri/ved & $\begin{array}{l}1 / A \cdot F \\
\cdot / \cdot \Delta V\end{array}$ & $\begin{array}{c}1 / \cdots \\
r \Delta / \cdots\end{array}$ & $\begin{array}{l}1 / 1 \cdot f \\
1 / 1 / Y\end{array}$ & شرايط & تفكر \\
\hline DTt & $\cdot \cdots r$ & १/GYT & $\begin{array}{l}. / 112 \\
.14\end{array}$ & $\begin{array}{l}1 / 44 \lambda \\
49 / 9 \& V\end{array}$ & $\begin{array}{l}. / 1 \Delta 8 \\
.101 V\end{array}$ & شرايط & لوب× تفكر \\
\hline
\end{tabular}

جدول ه- مقايسٔ بين ميانكَينهاى نمرات فعاليت امواج آلفا در نواحى مختلف مغزى.

\begin{tabular}{|c|c|c|c|c|c|}
\hline سطح معنى دارى & خطاى استاندارد & تفاوت ميانگين (I-J) & شرايط (J) & شرايط (I) & متغير \\
\hline $.1 \cdot 49$ & $\cdot 1 \cdot 1 \mathrm{~V}$ & $-\cdot / \cdot$ r & ناحيدُ مركزى & \multirow{2}{*}{ ناحيةٌ بِيشانى } & \multirow{6}{*}{ 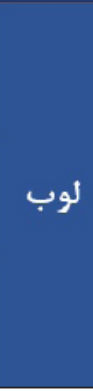 } \\
\hline בץ+1. & $.1 \cdot 10$ & זr/:-ט & ناحية كيجحَاهى & & \\
\hline $.1 \cdot r_{q}$ & $\cdot 1 \cdot 1 \mathrm{~V}$ & $\cdot / \cdot r \Lambda$ & ناحيدُ بِيشانى & \multirow{2}{*}{ ناحيةٌ مركزى } & \\
\hline$\cdot 19 \Delta \Delta$ & $\cdot 1 \cdot 14$ & $\cdot 1 \cdots \Delta$ & ناحية كيجكَاهى & & \\
\hline -1. & $.1 \cdot 10$ & אוץ•/• & ناحيةٌ بِيشانى & \multirow{2}{*}{ ناحية تَيجكَاهى } & \\
\hline .1900 & .1 .14 & $-\cdot / \cdot \Delta$ & ناحيدُ مركزى & & \\
\hline
\end{tabular}

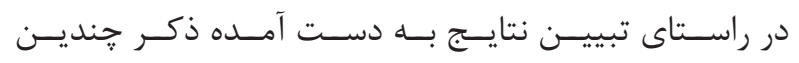

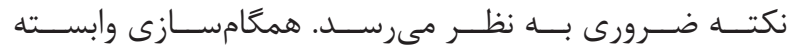

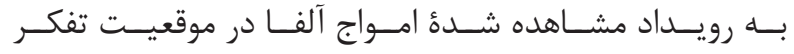

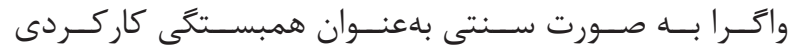

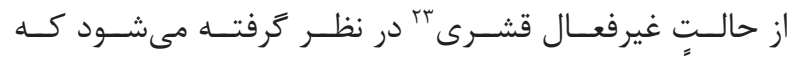

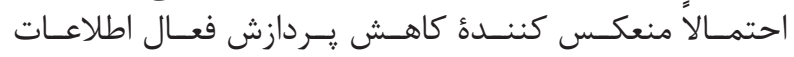

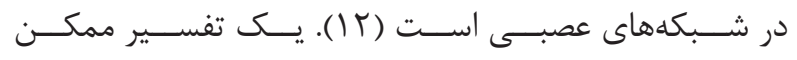

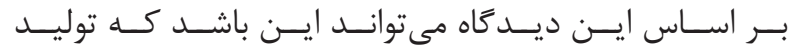

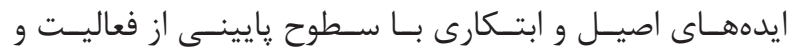

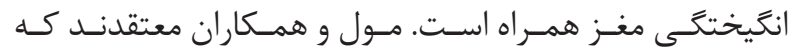

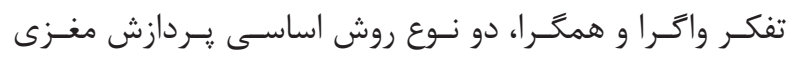

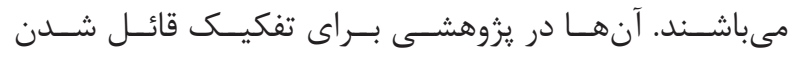

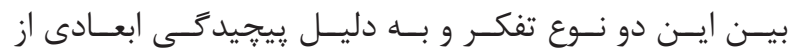

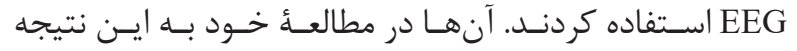

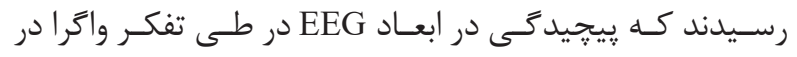

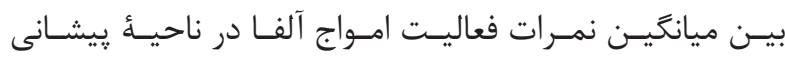

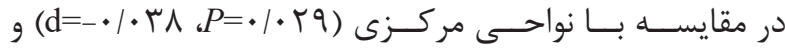

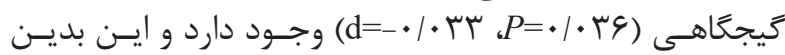

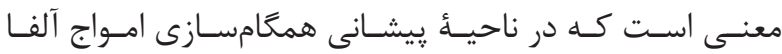

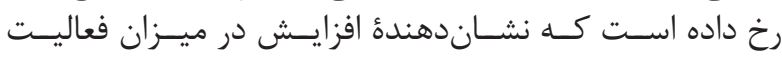

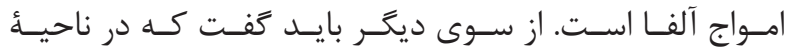

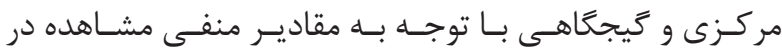

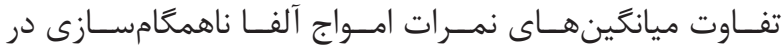

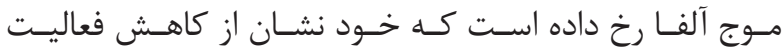

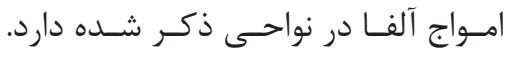

$$
\text { بحث و نتيجه كيرى }
$$

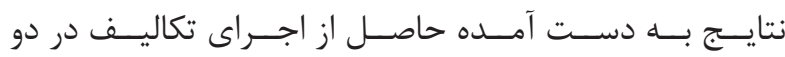

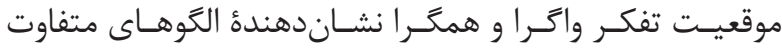

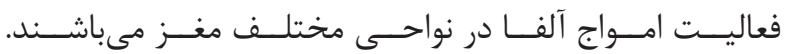

${ }^{23}$ Cortical idling 
هـردازش مربـوط بـهـ تكاليـف بــه كار بـرده شـده اسـت؛ بديسن

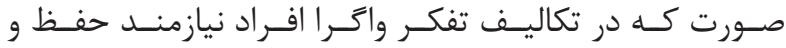

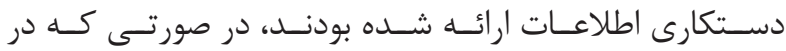

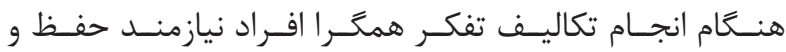

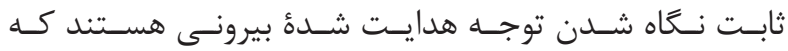

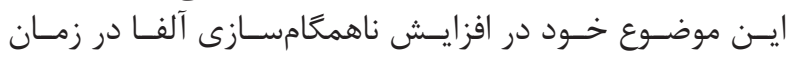

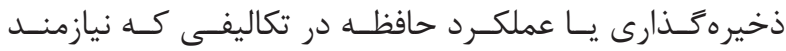

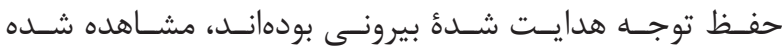

اسـت (Y) (Y).

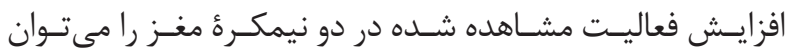

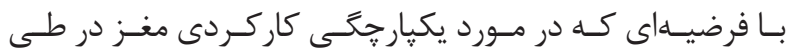

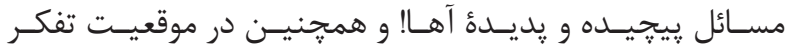

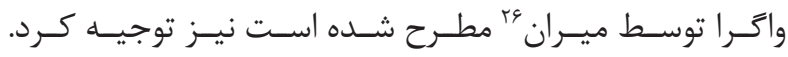

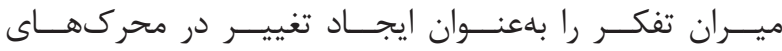

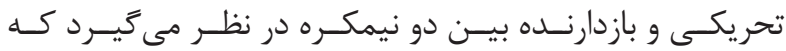

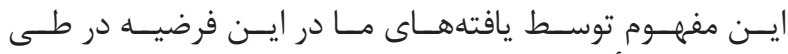

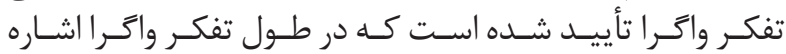

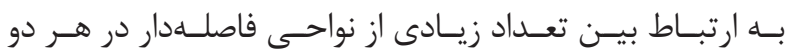

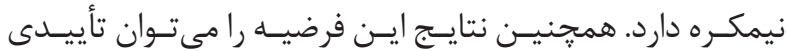

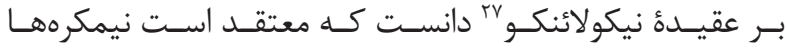

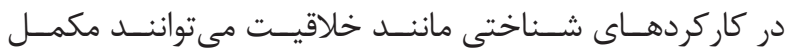

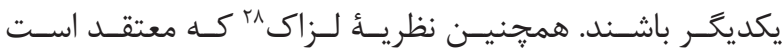

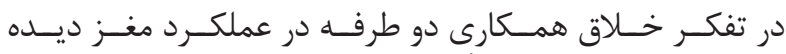

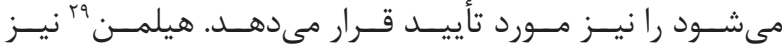

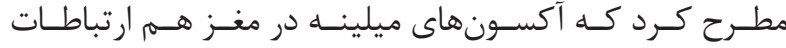

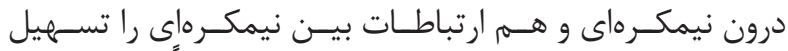

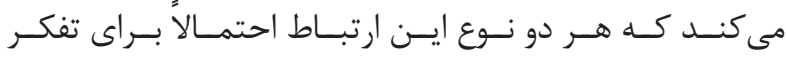

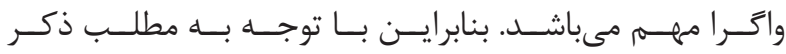

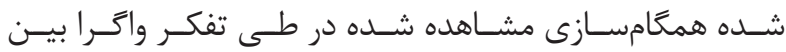

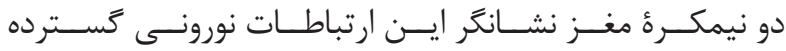

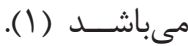

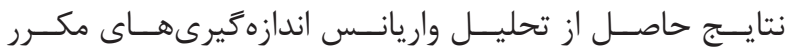

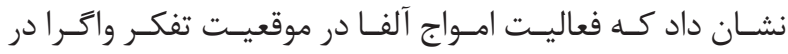

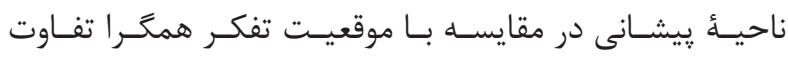

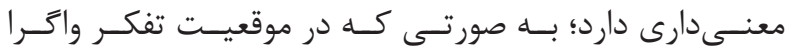

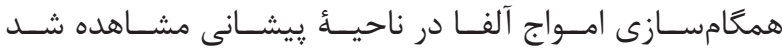

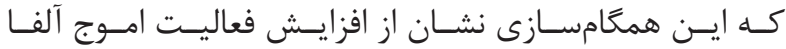

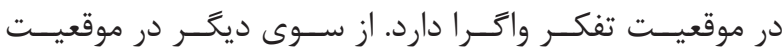

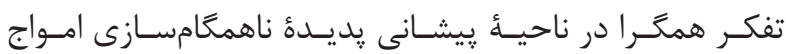

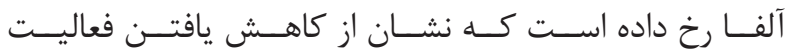

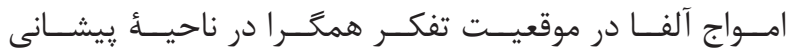

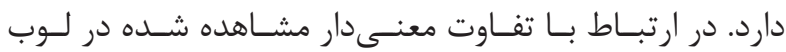

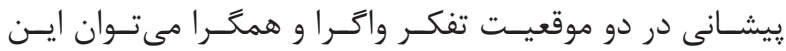

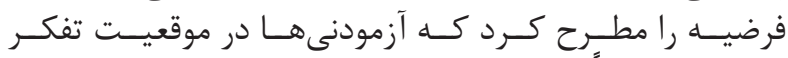

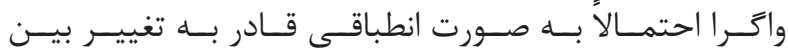

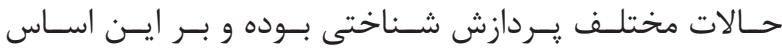

${ }^{24} \mathrm{Heb}$

${ }^{25}$ Bottom-up

${ }^{26}$ Miran 


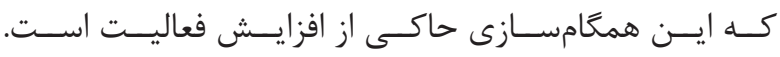

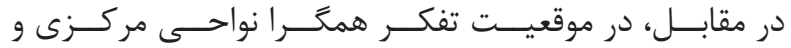

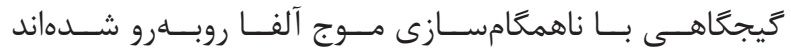

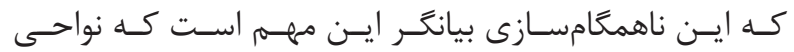

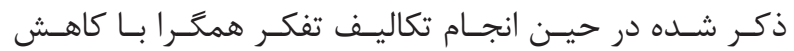

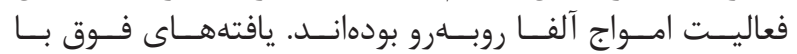

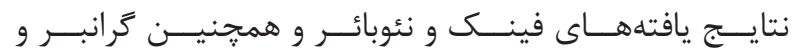

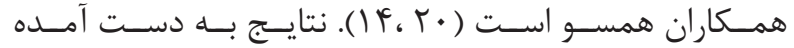

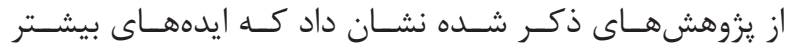

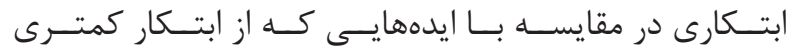

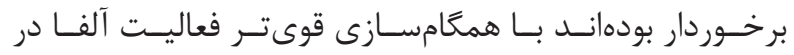

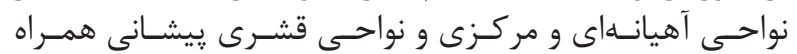

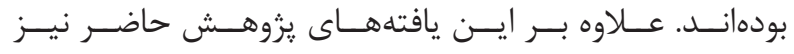

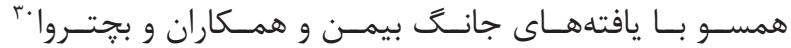

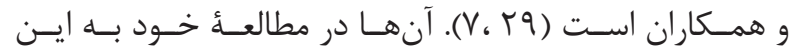

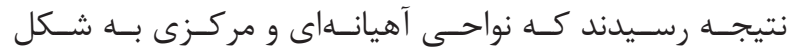

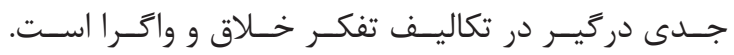
تشكر و قدردانى

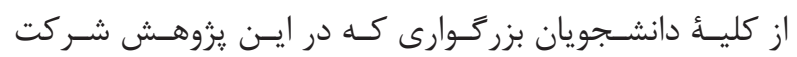

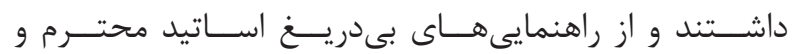

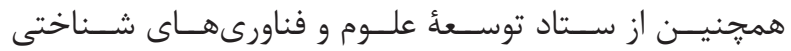

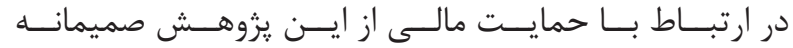

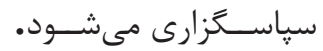

1. Bayrami M, Nazari MA, Andalib Kooraeim M. EEG patterns coherence in theta band during convergent and divergent thinking. Adv Cogn Sci. 2011; 13(2): 1-8.

2. Dietrich A. The cognitive neuroscience of creativity. Psychon Bull Rev. 2004; 11(6): 1011-26.

3. Flaherty A. Frontotemporal and dopaminergic control of idea generation and creative drive. J Comp Neurol. 2005; 493(1): 147-53.

4. Sternberg RJ, Lubart TI. Investing in creativity. Psychol Inq. 1993; 4(3): 229-32.

5. Mölle M, Marshall L, Wolf B, Fehm HL, Born J. EEG complexity and performance measures of creative thinking. Psychophysiology. 1999; 36(1): 95-104.

6. Razoumnikova O. Functional organization of different brain areas during convergent and divergent thinking: an EEG investigation. Cogn Brain Res. 2000; 10(1-2): 8-11.

7. Jung-Beeman M, Bowden EM, Haberman J, Frymiare JL, Arambel-Liu S, Greenblatt R, et al. Neural activity when people solve verbal problems with insight.

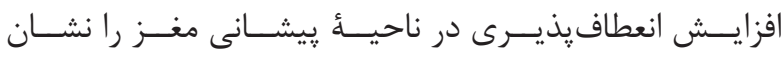

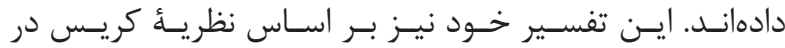

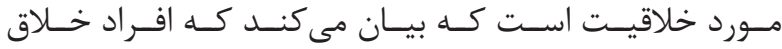

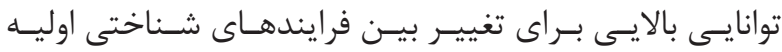

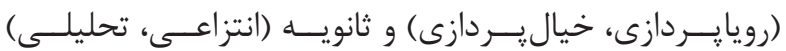

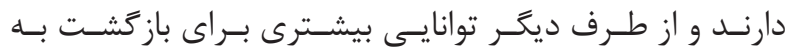

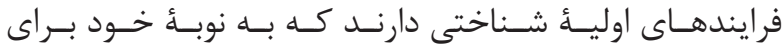

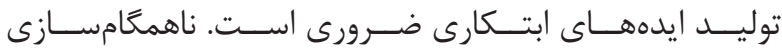

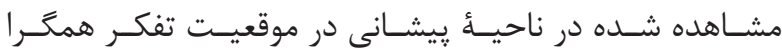

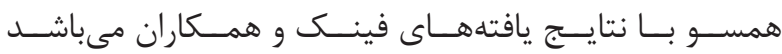

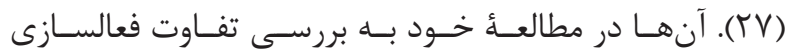

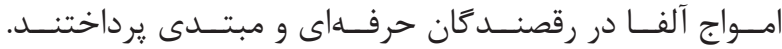

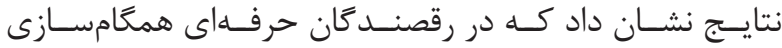

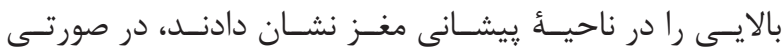

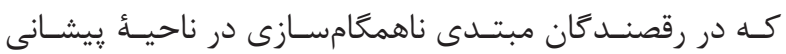

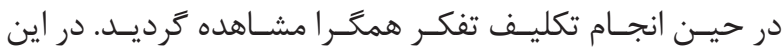

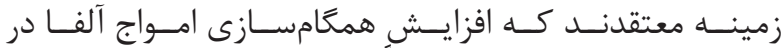

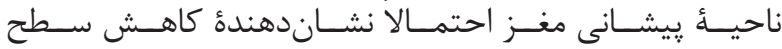

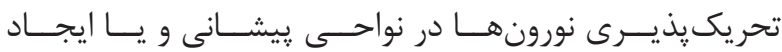

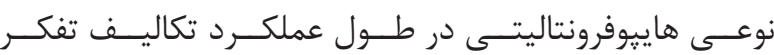

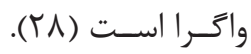

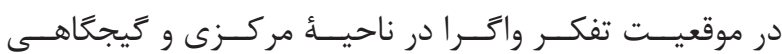

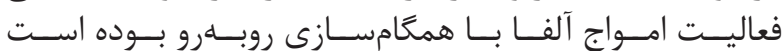

منابع

PLOS Biol. 2004; 2(4): e97. Doi: 10.1371/journal. pbio.0020097.

8. Folley B, Park S. Verbal creativity and schizotypal personality in relation to prefrontal hemispheric laterality: A behavioral and near-infrared optical imaging study. Schizophr Res. 2005; 80(2-3): 271-82.

9. Bhattacharya J, Petsche HJ. Drawing on mind's canvas: differences in cortical integration patterns between artists and non-artists. Hum Brain Mapp. 2005; 26(1): 1-14.

10. Benedek M, Schickel RJ, Jauk E, Fink A, Neubauer AC. Alpha power increases in right parietal cortex reflects focused internal attention. Neuropsychologia. 2014; 56: 393-400.

11. Klimesch WJ. Alpha-band oscillations, attention, and controlled access to stored information. Trends Cogn Sci. 2012; 16(12): 606-17.

12. Pfurtscheller G, Stancak Jr, Neuper CJ. Eventrelated synchronization (ERS) in the alpha band-an electrophysiological correlate of cortical idling: a review. Int J Psychophysiol. 1996; 24(1-2): 39-46.

${ }^{30}$ Bechtereva 
13. Martindale C, Mines DJ. Creativity and cortical activation during creative, intellectual and EEG feedback tasks. Biol Psychol. 1975; 3(2): 91-100.

14. Fink A, Neubauer AC. EEG alpha oscillations during the performance of verbal creativity tasks: differential effects of sex and verbal intelligence. Int $\mathrm{J}$ Psychophysiol. 2006; 62(1): 46-53.

15. Klimesch W, Sauseng P, Hanslmayr SJ. EEG alpha oscillations: the inhibition-timing hypothesis. Brain Res. 2007; 53(1): 63-88.

16. Fink A, Grabner RH, Benedek M, Neubauer AC. Divergent thinking training is related to frontal electroencephalogram alpha synchronization. Eur J Neurosci. 2006; 23(8): 2241-6.

17. Lustenberger C, Boyle MR, Foulser AA, Mellin JM, Fröhlich FJ. Functional role of frontal alpha oscillations in creativity. Cortex. 2015; 67: 74-82.

18. Dietrich A, Kanso RJ. A review of EEG, ERP, and neuroimaging studies of creativity and insight. Psychol Bull. 2010; 136(5): 822-48.

19. Jauk E, Benedek M, Neubauer AC. Tackling creativity at its roots: evidence for different patterns of EEG alpha activity related to convergent and divergent modes of task processing. Int J Psychophysio. 2012; 84(2): 219-25.

20. Grabner RH, Fink A, Neubauer AC. Brain correlates of self-rated originality of ideas: evidence from eventrelated power and phase-locking changes in the EEG. Behav Neurosci. 2007; 121(1): 224-30.

21. Fink A, Neubauer AC, Differences I. Eysenck meets martindale: the relationship between extraversion and originality from the neuroscientific perspective. Pers Individ Dif. 2008; 44(1): 299-310.

22. Saborimoghadam H. Impact of motivational manipulation and brain-behavioral systems on neurotransmission rates. $\mathrm{PhD}$ Thesis, Tabriz University. 2008.

23. Razumnikova OM. Gender differences in hemispheric organization during divergent thinking: an EEG inves tigation in human subjects. Neurosci Lett. 2004; 362(3): 193-5.

24. Fink A, Schwab D, Papousek IJ. Sensitivity of EEG upper alpha activity to cognitive and affective creativity interventions. Int J Psychophysiol. 2011; 82(3): 233-9.

25. Martindale C. Biological bases of creativity. Cambridge: Cambridge University Press; 1999. p. 137152.

26. Neubauer AC, FinkAJ, Differences I. Fluid intelligence and neural efficiency: effects of task complexity and sex. Pers Individ Dif. 2003; 35(4): 811-27.

27. Fink A, Grabner RH, Benedek M, Reishofer G, Hauswirth V,FallyM, etal.Thecreativebrain:Investigation of brain activity during creative problem solving by means of EEG and fMRI. Hum Brain Mapp. 2009; 30(3): 734-48.

28. Fink A, Graif B, Neubauer AC. Brain correlates underlying creative thinking: EEG alpha activity in professional vs. novice dancers. NeuroImage. 2009; 46(3): 854-62.

29. Bechtereva N, Korotkov A, Pakhomov S, Roudas M, Starchenko M, Medvedev SJ. PET study of brain maintenance of verbal creative activity. Int $\mathrm{J}$ Psychophysio .2004; 53(1): 11-20. 